Article

\title{
Evaluation of New Harvesting Methods to Reduce Weeds on Arable Fields and Collect a New Feedstock
}

\author{
Christoph Glasner ${ }^{1}{ }^{D}$, Christopher Vieregge ${ }^{2}$, Josef Robert ${ }^{1}$, Johanna Fenselau ${ }^{1}$, \\ Zahra Bitarafan ${ }^{3}$ (D) and Christian Andreasen ${ }^{3, *}$ (D) \\ 1 Fraunhofer Institute for Environmental, Safety, and Energy Technology UMSICHT, Osterfelder Str. 3, \\ 46047 Oberhausen, Germany; christoph.glasner@umsicht.fraunhofer.de (C.G.); \\ josef.robert@umsicht.fraunhofer.de (J.R.); johannafenselau@googlemail.com (J.F.) \\ 2 CLAAS Selbstfahrende Erntemaschinen GmbH, Muehlenwinkel 1, 33428 Harsewinkel, Germany; \\ christopher.vieregge@claas.com \\ 3 Department of Plant and Environmental Sciences, University of Copenhagen, Højbakkegaard Allé 13, \\ DK-2630 Taastrup, Denmark; zab@plen.ku.dk \\ * Correspondence: can@plen.ku.dk; Tel.: +45-35333453
}

Received: 12 January 2019; Accepted: 30 April 2019; Published: 5 May 2019

\begin{abstract}
During harvesting, grain, straw, and chaff with weed seeds are separated. The chaff is returned to the fields, resulting in weed problems in the subsequent crops. We estimated the fraction of weed seeds a combine harvester could potentially harvest and used various methods to collect the chaff and treat it with heat to kill weed seeds or reduce weed seed germination. Chaff with weed seeds was placed on top of the straw and afterwards baled with the straw as a method to remove weed seeds from the field. We exposed chaff with weed seeds to exhaust gas with various temperatures and durations to study whether this heating method could be used to reduce the input of viable weed seeds to the soil during harvesting. By collecting the shed weed seeds during the growing season, we estimated that a combine harvester could potentially harvest $41 \%, 11 \%$, and $100 \%$ of the seeds produced in the growing season by Bromus hordeaceus, Cirsium arvense, and Galium aparine, respectively. When the chaff was placed on top of the straw, $45 \%$ of the weed seeds stayed in the chaff fraction on top of the straw swath after one day, $35 \%$ got into the straw swath, and $20 \%$ past through the swath to the ground. Therefore, baling straw with chaff placed on the top only had a limited effect on reducing weed seed infestation. The study showed that thermal weed seed control during harvesting could potentially be applicable and incorporated in an integrated weed management approach.
\end{abstract}

Keywords: agricultural residues; chaff; combine harvester; environmental impact; feedstock; Harvest Weed Seed Control; HWSC

\section{Introduction}

Weeds are severe constraints for agricultural plant production. Herbicides have been the preferred solution for controlling weeds worldwide, but in recent decades herbicide-resistant weeds have become a growing problem [1,2]. The increasing interaction between continents and countries has also contributed to the spread of plant parts and seeds resulting in significant problems with invasive weeds [3]. Unfortunately, the development of herbicides with new mode of actions has not been successful since the 1980s [4]. Furthermore, unwanted side-effects of herbicide use have resulted in banning of many herbicides, and the agrochemical industry has been forced to withdraw many pesticides from the marketplace because of continuously stricter regulation of pesticides in the European Union [5]. This situation favors weed flora and threatens the livelihood of farmers as well as the food 
security $[6,7]$. Therefore, there is a need for new integrated weed management strategies to control weeds in the future and new means need to be developed to replace and supplement present methods. Furthermore, human activities have created unwanted climate change, and consequently, there is an urgent need to reduce $\mathrm{CO}_{2}$ emission and create a bio-based economy using agricultural biomass without affecting the food security negatively [8].

During the harvesting process, grains get separated from the rest and collected in a tank while straw is often removed, chopped or expelled to the field in rows in Europe. Afterwards, straw gets dried in the field, and in most cases collected and compacted into straw bales. The remaining harvested materials, called chaff, consist mainly of light plant residues as husks, dust and weed seeds. This fraction is blown out of the grain harvester and spread more or less uniformly on the field creating weed problems in the subsequent years.

Chaff is considered a useless material; however, it represents a significant amount of biomass and the exploitation of the chaff fraction may create new value-chains. Collecting and removing chaff from the field during harvesting might reduce the number of new weed seeds entering the soil seed bank considerably. In the European Union, approximately $152 \times 10^{6}$ tons of wheat and spelt are harvested annually of which approximately $50 \%$ of the weight of the material is grain, $25 \%$ straw and about $2 \%$ chaff $[9,10]$. This leads to a total biomass potential for chaff of about $38 \times 10^{6}$ tons year $^{-1}$ [11]. Spelt chaff has a heating value of $15.1-16.8 \mathrm{MJ} \mathrm{kg}^{-1}$ (e.g., wood pellets $16.3 \mathrm{MJ} \mathrm{kg}^{-1}$ ) [12,13]. If $33 \%$ of the chaff was removed and used as fuel, the theoretically energetic potential would be about $200 \mathrm{PJ}$ year ${ }^{-1}$. The energy could potentially be used for grain drying, heating, and power on the farms. For example, the electricity demand for drying of 1 ton of grain has been estimated to be 1.1-1.8 $\mathrm{MWh}^{-10 n s^{-1}}$ [14]. Thus, chaff constitutes potentially a self-generated renewable and cheap fuel which could contribute substantially to reduce $\mathrm{CO}_{2}$ emissions.

As chaff has a low bulk density it may be costly and time consuming to remove large volumes of chaff. Furthermore, removing all straw and chaff from the field may not be sustainable as it, when it is incorporated in the soil, contributes to maintaining the water holding capacity and the fertility of the soil. Alternative concepts, where the chaff fraction is returned to the field without adding harvested weed seeds to the soil seed bank also need to be considered. Such systems have been developed and practiced in Australia. Harvest weed seed control (HWSC) proposes collecting or destroying of weed seeds during harvesting before the seeds are returned to the field. Another method is to place chaff in a narrow-windrow and burn chaff and straw afterwards or place the chaff in wheel tracks to avoid a uniform spread of weed seeds [15-17]. However, such systems have not gained a foothold in Europe as stubble burning in general is prohibited in EU countries according to EC Regulation 1259/1999, unless it is permitted by competent authorities for plant health reasons. Seeds are generally sensitive to high temperatures, and as exhaust gas from a combine harvester constitutes a free energy resource it may be possible to utilize it to kill or reduce weed seed germination. Our project aimed to reduce weed infestation and thereby reduce the need for herbicide application and add additional benefits to the existing HWSC systems. We estimated how large a percentage of seeds produced during the growing season by three aggressive weed species a grain harvester could potentially collect during the harvest of winter wheat.

We also investigated concepts that, on the one hand, killed or reduced the germination ability of weed seeds, and on the other hand, utilized the chaff containing weed seeds to create new products. Three concepts were studied regarding applicability.

\section{- Concept 1: Heat treatment of weed seeds during harvesting.}

We explored how heat treatments with hot exhaust gas from a combine harvester could kill or reduce the germination ability of weed seeds. The chaff fraction can be brought into contact with the heat, or the weed seeds can be cleansed from the chaff and thereafter exposed to the heat. Afterwards, the chaff and the weed seeds can be returned to the field without causing a problem in the following growing seasons. However, this concept does not make an unexploited biomass feedstock available. 


\section{- $\quad$ Concept 2: Use of the total harvest}

In this concept, no harvested biomass is returned to the field. Grains are stored in the grain tank of the combine harvester while chaff and weed seeds are transferred to an accompanying trailer $[18,19]$. Removal of the total harvested biomass should only take place if it does not have any significant negative impact on the content of organic matter and the fertility of the soil. Such decisions must be based on knowledge about the crop rotation system, the soil type, soil texture, soil water capacity, and the present content of the soil organic matter.

\section{- $\quad$ Concept 3: Partial harvest}

We placed the chaff precisely on the straw rows to prevent a uniform distribution of weed seeds in the field. Afterwards, the swath can be collected and used for other purposed (feed, energy, and new materials) for example by compacting straw plus chaff into bales for further use.

\section{Materials and Methods}

\subsection{Weed Species}

In 2017 and 2018 the seed production and seed shattering of 10 randomly chosen plants of three weed species (Cirsium arvense (L.) Scop., Bromus hordeaceus L., Galium aparine L.) was recorded during the growing season in a winter wheat field in Taastrup $\left(55^{\circ} 38^{\prime} \mathrm{N}, 12^{\circ} 17^{\prime} \mathrm{E}\right)$, Denmark. All three species are common in fields of winter wheat in Northern Europe. Bromus hordeaceus is native to Eurasia. It is annual or biennial. The culms are mostly erect and can become up to $100 \mathrm{~cm}$ tall. In Northern Europe, it germinates in the autumn and can be a problematic weed in winter cereals and a severe problem in seed production of ryegrass (Lolium perenne L.) as it is difficult cleansing the seeds of $B$. hordeaceus from L. perenne [20]. Cirsium arvense is a perennial weed native throughout Europe. It can get $150 \mathrm{~cm}$ tall and forms extensive clonal colonies from thickened roots that send up numerous erect shoots during the growing season. Seeds are 4-5 mm long with a feathery pappus, which assists in wind dispersal [21]. Galium aparine L. is an annual plant also native to Europe with creeping straggling stems attaching themselves with small hooked hairs which grow out of the stems and leaves. They branch and grow along the ground and up and over the crop plants [22].

\subsection{Estimation of Harvestable Weed Seeds}

A wheat field was sown 27 September 2016 and harvested 15 August 2017. Another field was sown 18 October 2017 and harvested 31 July 2018. Just before flowering ten plants of each species were randomly selected and surrounded by a porous net (precision woven open mesh fabrics: SEFAR NITEX 06-475/56, Sefar, Germany; mesh opening: $475 \mu \mathrm{m}$; opening area: 56\%). The nets tightly surrounded the plants at the soil surface to avoid seeds loss to the soil surface (Figure 1). The nets were visited each week to record the start of seeds shedding. The bottom of the nets was vacuum cleaned with a handheld vacuum cleaner collecting the shed seeds. For each species, the collecting started when seed shedding had occurred in half of the nets. Hereafter, seeds were collected every 6-8 days depending on the weather condition until wheat harvest and stored in paper bags. Just before harvest, weed plants were cut $15 \mathrm{~cm}$ above the soil surface (normal harvest height) as no plants produced seed below this height. The number of seeds remaining on the weed plants was counted. The ratios between harvestable seeds and seeds shed before harvest were determined. Analysis of variance (ANOVA) followed by Fisher's least significant difference (LSD) for means separation was done using SAS ${ }^{\circledR}$ version 9.4 software [23]. 

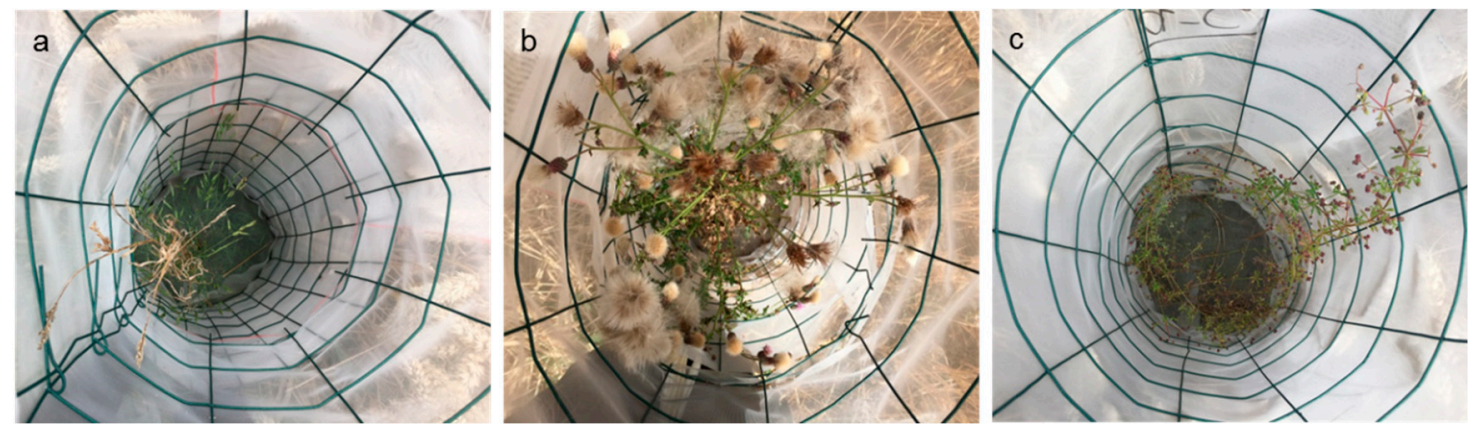

Figure 1. A plant of (a) Bromus hordeaceus, (b) Cirsium arvense, and (c) Galium aparine in nets to record seed shedding during the growing season of winter wheat.

\subsection{Field Tests with Wheat Chaff}

The fate of weed seeds in the chaff fraction was studied. Field tests were conducted in the harvesting seasons in 2016 and 2017.

In 2016, fields tests in winter wheat fields in Balje, North-western of Germany (53 $50^{\prime} 44^{\prime \prime}$ North, $9^{\circ} 9^{\prime} 10^{\prime \prime}$ East) were conducted. The aim was to study in which fraction-straw or chaff-A. myosuroides seeds can be found. The combine harvester company CLAAS Selbstfahrende Erntemaschinen GmbH modified a combine harvester to make the analyses possible and it was used both years. Therefore, a bracket for sheets was attached at the back of the combine harvester. By releasing the bracket, the sheet was rolled out, in such a way that the swath and the chaff could be collected separately. The sheets had a length of $10 \mathrm{~m}$ (Figure 2a,b). Both sheets unrolled simultaneously and were placed one above the other. The lower one collected the chaff solely while the upper one contained the harvested straw. This made it possible to characterize the chaff fraction and describe the composition, structure and the fate of harvested weed seeds. The chaff and the straw were sieved in order to determine the content of $A$. myosuroides seeds. Five samples of chaff of approx. $200 \mathrm{~g}$ were dived into two fractions using a $3 \mathrm{~mm}$ vibrating sieve for $15 \mathrm{~min}$. Afterwards, the fine fraction was further separated using a sieving tower. Sieves with mesh sizes of 4.0, 2.0,1.4, and $1 \mathrm{~mm}$ were used. The sieving time was $10 \mathrm{~min}$.
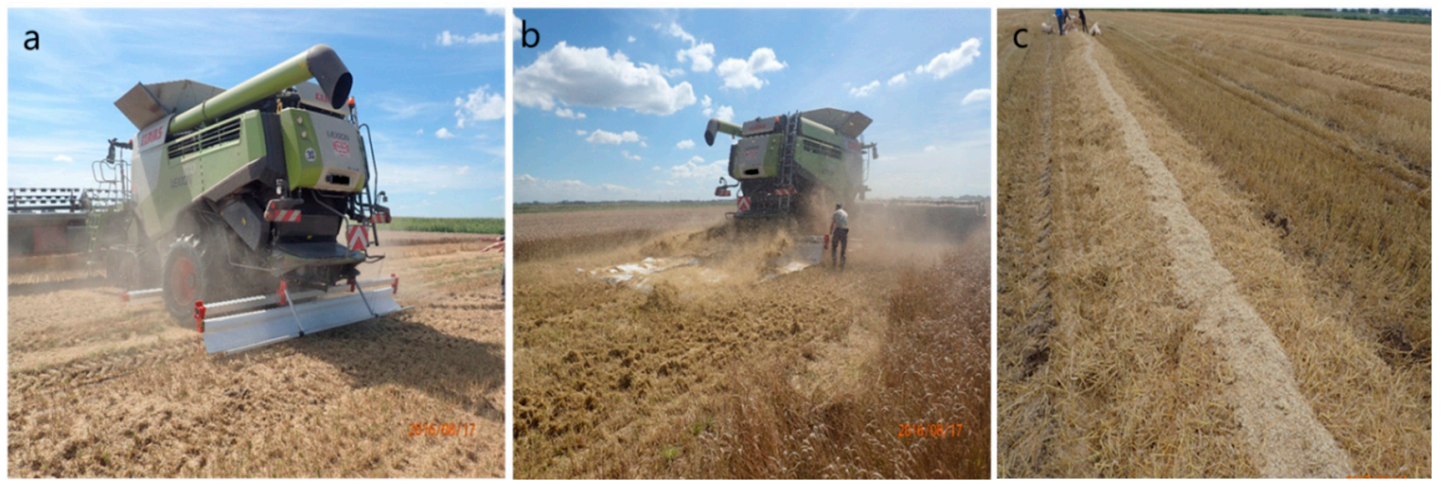

Figure 2. (a) Unrolling sheet installations below the combine harvester and (b) in operation. (c) Chaff placed on the straws.

In 2017, tests in winter wheat fields in Krummendeich, North-western of Germany (53 $49^{\prime}$ North, $9^{\circ} 12^{\prime}$ East) were conducted to analyze the concept of compositing chaff on the straw swatch and its subsequent baling (Figure 2c). The test was repeated three times. Just before harvest four samples were taken from the field with an area of $70 \times 70 \mathrm{~cm}$ to determine the total biomass of the wheat and $A$. myosuroides. The areas were cut $5 \mathrm{~cm}$ above the ground. The purpose of the tests in 2017 was to analyze the concept of depositing chaff on the straw swath and its subsequent baling (Figure 2c). Samples were taken from three different sheets (3 replicates) with a length of $10 \mathrm{~m}$. 
The straw swath was placed on a sheet and the chaff was placed on the top of the straw swath. Samples were taken from the chaff on top of the swath, from the straw swaths, and the material under the straw swaths before balling. All samples were separated in a fine $(<1 \mathrm{~mm})$, a medium $(\geq 1 \mathrm{~mm}$ and $<2 \mathrm{~mm}$ ) and a coarse fraction ( $\geq 2 \mathrm{~mm}$ ) by sieves. Additionally, to the first sieving step, $43 \mathrm{~g}$ of the medium fraction of the first sieving trial were sieved again in a sieve tower and separated into four sub-fractions (A > $1.7 \mathrm{~mm}$; $>1.4 \mathrm{~mm}$; $>1.12 \mathrm{~mm}$; D > $1 \mathrm{~mm}$ ). The distribution of weed seeds in each sub-fraction was visually inspected. In one of the three replicates, the total fraction of chaff and the total fraction of material under the swath on the sheet were weighed.

\subsection{Thermal Treatment of Seeds}

Simulations and laboratory experiments were done to test methods to kill or reduce the germination ability of the weed seeds. The aim was to determine parameters that made it feasible to implement the principles in a combine harvester.

\subsubsection{Simulation of Heat Transfer to Model Seeds}

By using the computational fluid dynamics software COMSOL Multiphysics ${ }^{\circledR}$, which is based on the finite element method [24], we simulated the temperature profile inside a seed after heat exposure. A temperature of at least $80^{\circ} \mathrm{C}$ in the middle of the seed was targeted. This temperature can be lethal for weed seeds [25-27]. The radiation and forced convection of the heat were analyzed. A model seed was approximated as a cylinder with a height of $2 \mathrm{~mm}$ and a diameter of $1 \mathrm{~mm}$. Two different gas velocities were simulated for convective heat transport. Those velocities were the minimum $\left(0.08 \mathrm{~m} \mathrm{~s}^{-1}\right)$ and maximum $\left(8.8 \mathrm{~m} \mathrm{~s}^{-1}\right)$ speed of the gas above the surface of a weed seed within a combine harvester to mimic realistic conditions. Outside those limits, the harvesting process would be disturbed. Besides the gas velocity and the mechanism of heat transfer, we also analyzed the influence of the temperature $\left(50-500{ }^{\circ} \mathrm{C}\right)$ and the time of heat exposure $(0-60 \mathrm{~s})$.

\subsubsection{Heating Chaff Containing Seeds of Centaurea cyanus L. with Exhaust Gas}

Exhaust gas from a combine harvester was used to kill or reduce seed germination of the weed species Centaurea cyanus L. A sieve containing a sample of chaff with weed seeds was placed above an exhaust pipe and covered with a porous cover. The exhaust gas was kept at a constant temperature by controlling the energy flow to the engine. Centaurea cyanus was chosen as a model plant because it has large seeds $(3.4 \times 1.7 \times 1.2 \mathrm{~mm})$ [28] and therefore was expected to be less sensitive to heat than species with small seeds. The seeds were mixed in the chaff to mimic a realistic situation as the chaff may protect the seeds from the heat. Chaff samples containing 100 seeds of $C$. cyanus were treated with exhaust gas with a temperature of $100^{\circ} \mathrm{C}$ and $150{ }^{\circ} \mathrm{C}$ for $1,2,5$, and $10 \mathrm{~s}$. Each treatment was replicated four times. Afterwards, chaff samples were spread evenly on soil placed in $52 \times 26 \mathrm{~cm}$ trays and after that covered by a thin layer of a mixture of clay soil and sand. Untreated chaff samples containing C. cyanus seeds were used as controls. The trays were placed in a greenhouse and watered from the bottom, and the germination was recorded after 30 days.

\section{Results}

\subsection{Estimation of Harvestable Weed Seeds}

Bromus hordeaceus only occurred in the field in 2017. On average plants produced 894 seeds and $41.3 \%$ remained on the plants at harvest. Seed shattering started between 11-18 July. The highest number of seeds were shed between 18-24 July which was significantly more than in the other weeks $(\mathrm{p}=0.01)$ (Figures $3 \mathrm{a}$ and 4$).$ 

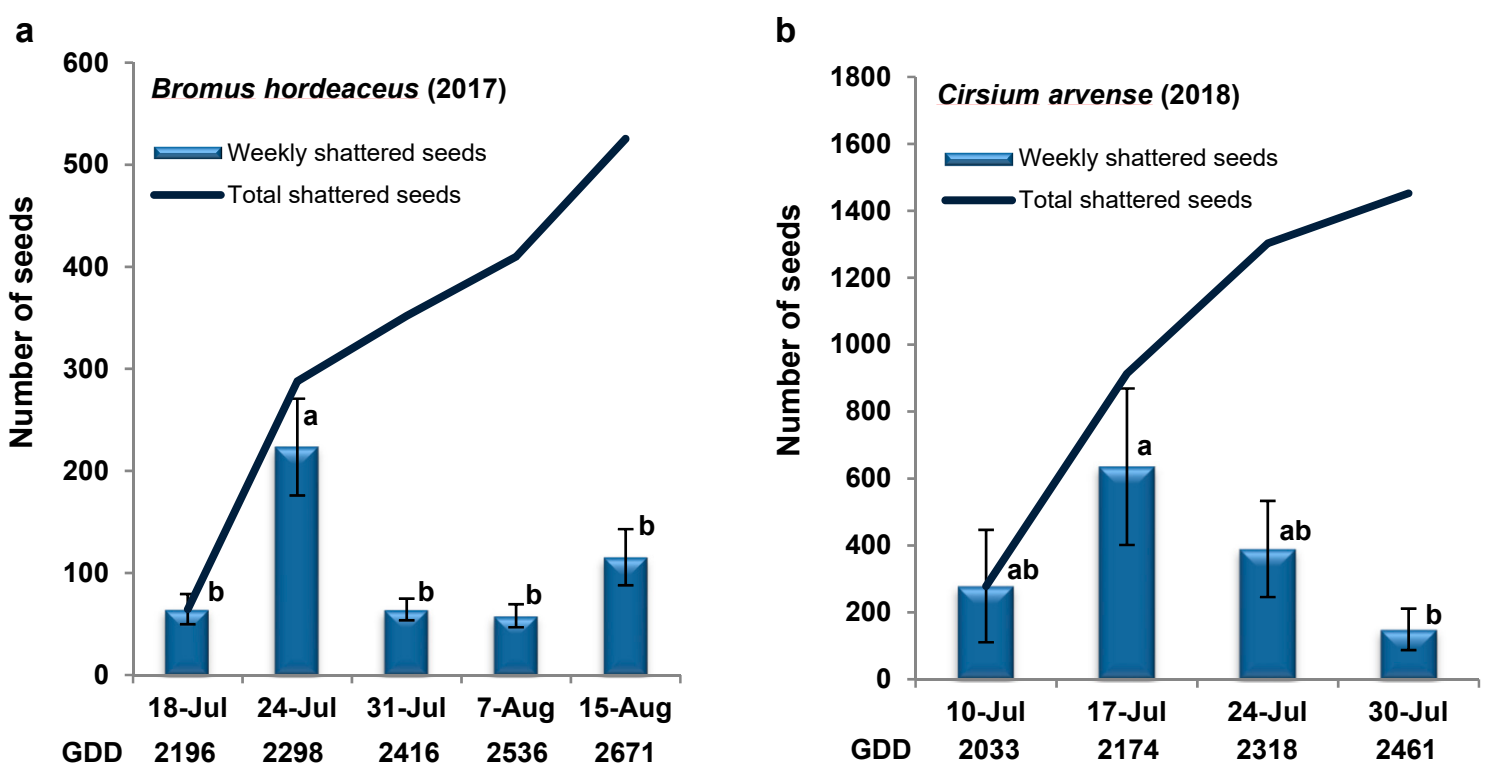

Figure 3. Average weekly and accumulated seed shedding per plant $(\mathrm{N}=10)$ of (a) Bromus hordeaceus and (b) Cirsium arvense during the growing season of winter wheat. GDD $=$ Growth Degree Days $=$ sum of daily mean temperatures above 0 from the date the winter wheat was sown. Bars show standard deviation. Columns with different letters are statistical significantly different.

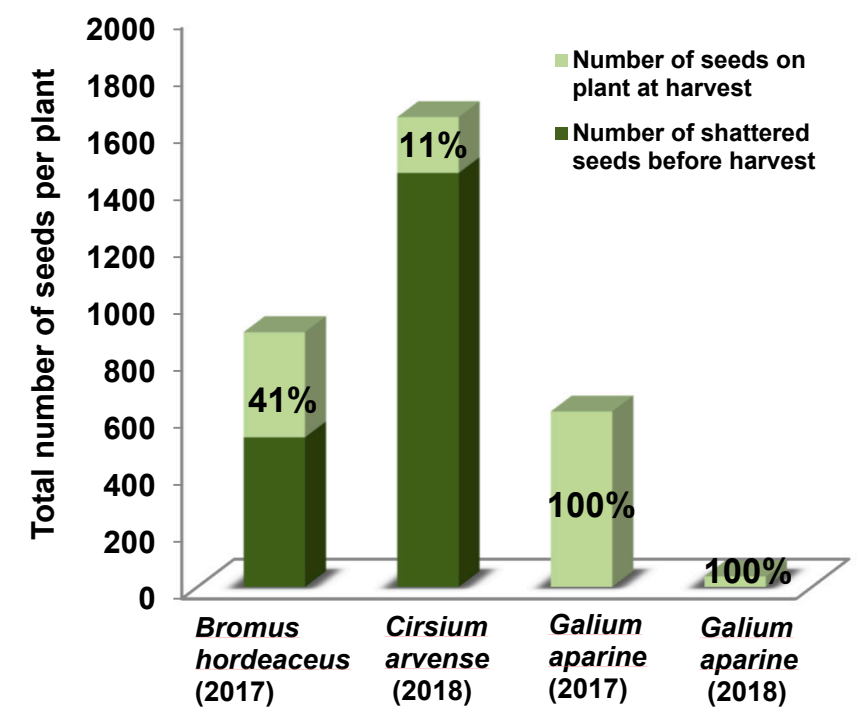

Figure 4. The total number of seeds and number of seeds shattered before wheat harvest of Bromus hordeaceus, Cirsium arvense and Galium aparine.

Cirsium arvense was sampled in 2017 and 2018 but only produced seeds in 2018. On average plants produced 1647 seeds but only $11.9 \%$ remained on the plant a harvest. Seed shattering started between 3-10 July, and there was no significant difference between the weekly seed shed (Figures $3 \mathrm{~b}$ and 4).

Galium aparine plants produced in average 616 and 37 seeds plant $^{-1}$ in 2017 and 2018, respectively. The species did not shed any seeds before harvest in both growing seasons (Figure 4).

\subsection{Field Experiment with Wheat Chaff}

In 2016, the weight of $A$. myosuroides made up $4.11 \% \pm 3.14 \%$ of the total biomass of the harvested plots in the wheat field. The infestation of $A$. myosuroides was not homogeneous. The biomass of A. myosuroides ranged from $0 \%$ to $9.1 \%$. In 2017, the field had an even larger infestation of $A$. myosuroides. On average, more than 40 ears $\mathrm{m}^{-1}$ of $A$. myosuroides were found, even though their distribution 
was not uniform (more than 150 ears $\mathrm{m}^{-1}$ were recorded in some parcels). The relative biomass of A. myosuroides was not determined in 2017 but the absolute number of weed seeds in the collected samples were determined.

\subsubsection{Sieving of Chaff (2016)}

On average, the fine fraction of chaff $(<3 \mathrm{~mm})$ taken from the 2016 field tests was $35 \% \pm 5 \%(\mathrm{w} / \mathrm{w})$ of the total chaff. The chaff consisted of husks (length of about $0.8 \mathrm{~mm}$ ) and straw pieces (length of 1 to $20 \mathrm{~cm}$ ) and had a bulk density of $34 \mathrm{~g} \mathrm{~L}^{-1}$ and water content of $7.5 \%$. All fractions were analyzed visually. No weed seeds of $A$. myosuroides were found in the large fraction. Table 1 shows the mass distribution of the accumulated fine fraction of the chaff as a result of the subsequent sieve tower experiments. By visual inspection it was determined that almost all seeds of $A$. myosuroides accumulated between 1.0 and $1.4 \mathrm{~mm}$.

Table 1. Mass distribution of the fine fraction of the chaff $(\mathrm{N}=5)$.

\begin{tabular}{cccccc}
\hline Cut-off & $<1.0 \mathrm{~mm}$ & $<\mathbf{1 . 4} \mathrm{mm}$ & $<2.0 \mathrm{~mm}$ & $<4.0 \mathrm{~mm}$ & $>\mathbf{4 . 0} \mathbf{~ m m}$ \\
\hline $\mathrm{w} / \mathrm{w}$ & $41 \%$ & $12 \%$ & $14 \%$ & $33 \%$ & $0 \%$ \\
\hline
\end{tabular}

\subsubsection{Chaff Deposition on the Straw Swath (2017)}

The results showed that placing chaff on the straw swath will lead to a distribution of weed seeds into all fractions. Weed seeds were also found in the straw swaths, and under the swaths. The results are summarized in Table 2.

Table 2. Results of sieving experiments (indices belong to fractions sieved by a mesh size of: $\mathrm{A}>1.7$ $\mathrm{mm}$; $\mathrm{B}>1.4 \mathrm{~mm}$; C > $1.12 \mathrm{~mm}$; $\mathrm{D}>1 \mathrm{~mm}$ ). $\mathrm{m}=$ mass, $\mathrm{n}=$ total number.

\begin{tabular}{|c|c|c|c|c|c|c|c|c|c|c|c|c|}
\hline & & \multirow{2}{*}{\multicolumn{3}{|c|}{ Sieving of Sample }} & \multicolumn{7}{|c|}{ Sieving of $\mathbf{m}_{\text {medium }}$} & \multirow[b]{3}{*}{$\begin{array}{c}\text { Number of } \\
\text { A. myosuroides } \\
\text { seeds }\end{array}$} \\
\hline & & & & & $\mathbf{A}$ & & 3 & & & & & \\
\hline Replica & Sample & $\mathbf{m}_{\text {fine }}$ & $\mathrm{m}_{\text {medium }}$ & $\mathbf{m}_{\text {coarse }}$ & $\mathrm{m}_{\mathrm{A}}$ & $\mathbf{m}_{\mathrm{B}}$ & $\mathbf{n}_{\mathbf{B}}$ & $\mathrm{m}_{\mathrm{C}}$ & $\mathbf{n}_{\mathrm{C}}$ & $\mathbf{m}_{\mathrm{D}}$ & $\mathbf{n}_{\mathbf{D}}$ & \\
\hline \multirow{4}{*}{1} & & [g] & [g] & [g] & [g] & [g] & - & [g] & - & [g] & - & - \\
\hline & Chaff & 4.2 & 217 & 1203 & 36.1 & 0.3 & 74 & 1.0 & 284 & 1.0 & 70 & 428 \\
\hline & Straw & 52 & 238 & 5380 & & & & & & & & \\
\hline & Material under swath & 4.3 & 64 & 570 & 38.8 & 0.2 & 64 & 0.5 & 82 & 0.5 & 27 & 173 \\
\hline \multirow{3}{*}{2} & Chaff & 4.8 & 208 & 1150 & 37.3 & 0.6 & 144 & 0.8 & 188 & 0.7 & 52 & 384 \\
\hline & Straw & 36 & 110 & 5792 & 35.3 & 0.8 & 165 & 1.6 & 203 & 1.0 & & 368 \\
\hline & Material under swath & 2.8 & 46 & 375 & 38.9 & 0.2 & 70 & 0.7 & 99 & 0.4 & 19 & 188 \\
\hline \multirow{3}{*}{3} & Chaff & 7.1 & 288 & 1478 & 33.9 & 0.3 & 79 & 1.3 & 377 & 1.1 & 77 & 533 \\
\hline & Straw & 56 & 171 & 4927 & 36.6 & 0.6 & 118 & 1.3 & 163 & 0.6 & & 281 \\
\hline & Material under swath & 4.2 & 87.3 & 502 & 36.8 & 0.2 & 52 & 0.8 & 118 & 0.5 & 28 & 198 \\
\hline
\end{tabular}

In addition, we collected the total fraction of chaff and the total fraction of material under the swath from one of the sheets (replica 1). We measured $10.434 \mathrm{~kg}$ of chaff and $7.374 \mathrm{~kg}$ of material under the swath on the sheet. This means that $41.4 \%$ of the total chaff was trickling through the swaths, and only $58.6 \%$ remained on top of the swaths after one day. In replica 2 and 3 we estimated that $47 \% \pm 5.9 \%$ of the weed seeds stayed in the chaff fraction on top of the straw swath, $33.3 \% \pm 5.7 \%$ of weed seeds were inside the straw swaths, and $19.8 \% \pm 0.2 \%$ of weed seeds ended under the swaths based on the sieving experiments (Table 2).

\subsection{Simulation Study}

Figure 5 shows an example of the distribution of temperatures within a model seed based on the simulation model. When the temperature was $200^{\circ} \mathrm{C}$, and the gas velocity was $0.08 \mathrm{~m} \mathrm{~s}^{-1}$ the temperature in the middle of the seed was $58.3^{\circ} \mathrm{C}$ after $2 \mathrm{~s}, 68.2{ }^{\circ} \mathrm{C}$ after $2.5 \mathrm{~s}$, and $77.6{ }^{\circ} \mathrm{C}$ after $3 \mathrm{~s}$. Simulation of the temperature distribution based on radiative heat at $100^{\circ} \mathrm{C}$ showed that the 
core of the model seed did not reach the desired $80{ }^{\circ} \mathrm{C}$. Different heat transfer velocities have to be taken into account when these results are transferred into real conditions where seed sizes and morphology, and moisture content vary. The gas velocity had a significant effect on the heat transfer. A gas temperature between $150{ }^{\circ} \mathrm{C}$ and $250{ }^{\circ} \mathrm{C}$ and a gas velocity of $8.8 \mathrm{~m} \mathrm{~s}^{-1}$ in $2 \mathrm{~s}$ gave a temperature of $80^{\circ} \mathrm{C}$ in the middle of the model seed (Figure 6).


Figure 5. Simulated temperatures in a model seed exposed to a gas temperature of $200{ }^{\circ} \mathrm{C}$ and a gas velocity of $0.08 \mathrm{~m} \mathrm{~s}^{-1}$ for $2 \mathrm{~s}, 2.5 \mathrm{~s}$, and $3 \mathrm{~s}$.

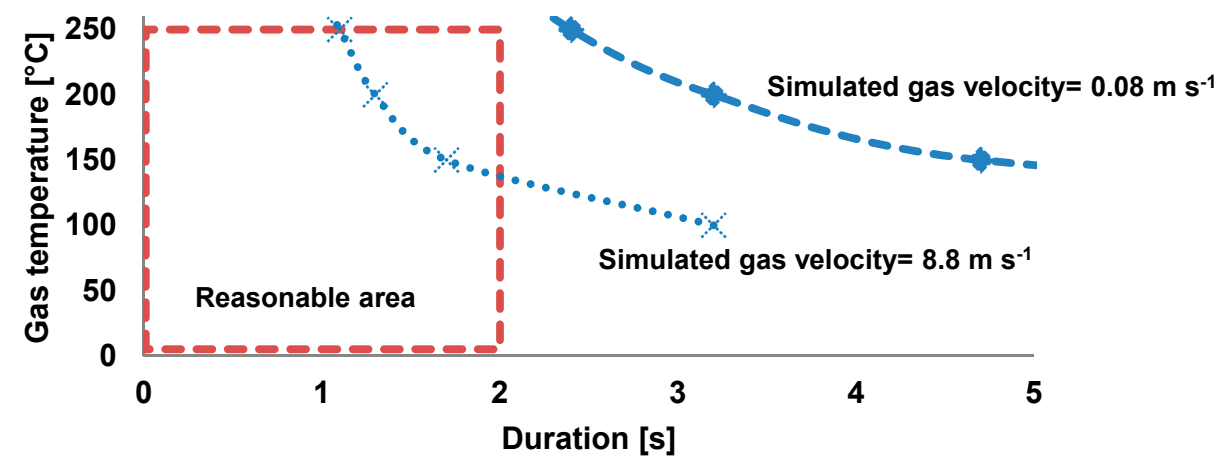

Figure 6. Two temperature curves for a model seed $\left(80^{\circ} \mathrm{C}\right.$ in the middle of the seed) in relation to the gas temperature, the velocity of the gas and the time of exposure. The red marked area indicates the combinations of temperature and duration that are realistic to obtain with a commercial grain harvester.

\subsection{Heating Chaff Containing Seeds of Centaurea Cyanus with Exhaust Gas}

Figure 7 shows the effect of the heat treatments of the chaff containing C. cyanus. Exposing the chaff with seeds to $100{ }^{\circ} \mathrm{C}$ hot exhaust gas for $1,2,5$ and $10 \mathrm{~s}$ reduced the germination percentage in average 5.9, 31.5, 46.6, and 53.3\%, respectively. Exposing chaff with seeds to $150{ }^{\circ} \mathrm{C}$ for $1,2,5$ and $10 \mathrm{~s}$ reduced the germination percentage in average with 4.3, 25.7, 73.9, and 98.8\%, respectively (Figure 7). 


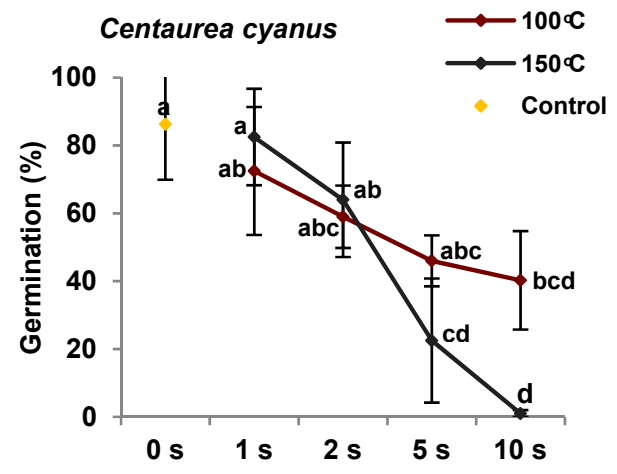

(a)

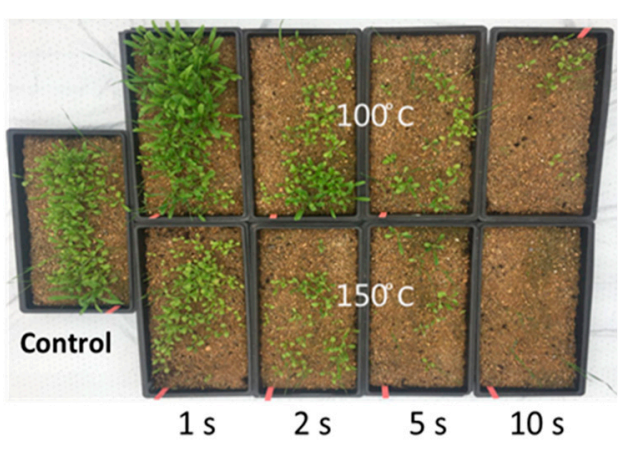

(b)

Figure 7. (a) Average germination percentage of Centaurea cyanus $(\mathrm{N}=4)$ after the chaff with seeds has been exposed to a temperature of $100{ }^{\circ} \mathrm{C}$ or $150{ }^{\circ} \mathrm{C}$ for $1,2,5$, and $10 \mathrm{~s}$. Bars show standard deviation. (b) Example of a replicate ordered after treatments.

\section{Discussion}

\subsection{Estimation of Harvestable Weed Seeds}

Seed shedding of three common weed species with very different growth and morphology were studied. The aim was to estimate how large a percentage of the total seeds production during the growing season of wheat the weed species retained on the plants at wheat harvest and therefore could potentially be collected by a combine harvester. All seeds were retained on G. aparine at wheat harvest in both years. Cirsium arvense only produced seeds in 2018 and only retained $11 \%$ of the seeds on the plants at harvest. Seed shattering of B. hordeaceus was only recorded one year where $41 \%$ of the seeds were retained on the plants at harvest. Different weather conditions characterized the two years. In 2017, the summer in Denmark was cold, wet and sun poor with no days with temperatures above $30{ }^{\circ} \mathrm{C}$. This might be the reason why C. arvense did not set seeds in 2017 . However, data based on one or two seasons may not give a representative picture of the seed shattering patterns of a species.

In contrast, the weather in 2018 was unusually dry, warm, and sunny with many days with temperatures above $30^{\circ} \mathrm{C}$. The summer was the warmest since 1874 [29]. Consequently, the conditions for growth and seed production were very different. Weed species have very different seed shedding patterns. Some species shatter most of the seeds before harvest while others like G. aparine keep their seeds on the plant until crop harvest. Bitarafan and Andreasen [30] studied in two growing seasons in winter wheat fields in Denmark the seed shedding of the two aggressive weed species Alopecurus myosuroides Huds. and Apera spica-venti L. In 2017, the seed retention on the plants at wheat harvest was $29.3 \%$ for A. myosuroides and $53.2 \%$ for A. spica-venti. In 2018, A. myosuroides retained $37.9 \%$ and $A$. spica-venti retained $16.7 \%$. Seed shedding patterns are highly depending on climate and growth conditions. It has been reported from Australia and Spain that Lolium rigidum Gaud. (annual ryegrass) retained between $80 \%$ and $96 \%$ of the seeds at wheat harvest [31,32] The levels of Avena fatua L. (wild oat) seed retention has been reported to be between $20 \%$ and $50 \%$ in Canada [33,34] and about $20 \%$ in the UK [35]. In the UK and Italy, the seed retention of Bromus diandrus Roth (brome grass) and Raphanus raphanistrum L. (wild radish) was estimated to be $40-50 \%$ [36].

Collecting weed seeds with a grain harvester and removing the seeds from the field, or kill or reduce the seed germination before the seeds are returned to the field could potentially reduce weed seed infestation substantially of some species like G. aparine but would have limited impact on the soil seed bank of other weed species like A. spica-venti, B. hordeaceus and C. arvense. 


\subsection{Field Experiment with Wheat Chaff}

The chaff sieving tests showed that it was not necessary to remove the total chaff fraction from the field to prevent the spreading of the harvested seeds of $A$. myosusoides. In our case, only $4.2 \%$ of the whole chaff (the fraction between 1.0 and $1.4 \mathrm{~mm}$ ) needs to be removed or $9.1 \%$ if we consider a cut-off between 1.0 and $2.0 \mathrm{~mm}$. Thus, the development of appropriate sieving technology for chaff in the combine harvester which could clean out particle with a size between of 1.0 and $2.0 \mathrm{~mm}$ could reduce the amount of chaff that need to be removed from the field and save transport costs for chaff containing weed seeds significantly. However, weed species have very differed seed sizes. Thus, depending on the weed problem in the field the sieving technology should be adjustable to produce other cut-off fractions.

We used special equipment to place the chaff on the straw swaths to avoid weed seed infestation, but the method had some limitations. The swaths should not be moved before baling to avoid that the weed seeds fall to the ground. However, this can be a problem as the straw often needs to be turned around to dry in the wind, because it cannot be baled when it is wet. The experiments also showed that $40 \%$ of the placed chaff remained on the ground below the swaths after the collection. The fraction could be even larger if winds are spreading the chaff with weed seeds from the top of the straw. We conclude that baling straw and chaff together is generally possible, but a limited weed seed removal strategy.

We recommend collecting the chaff in a controlled manner, for example in an accompanying trailer. Collecting chaff on a trailer does not affect the harvest velocity directly, and the necessary technical adaptions on a conventional harvester are possible without significant costs. Although collecting chaff itself does not change the harvest velocity, closing the cleaning area within the combine harvester, which is necessary to redirect the chaff, lowers the performance by $10-25 \%$ at high grain throughputs. The collection of loose chaff during harvesting allows further treatment of chaff besides the fields to adjust it to the demands of further exploitation. Combustion experiments of chaff showed that sorting of chaff before compressing can be beneficial for the handling and the combustion application. Furthermore, chaff can be compressed to briquettes or pellets to ease the handling, lower the transport costs and to decrease the storage volume of chaff [37]. Collecting chaff directly during the harvest in a trailer has the advantage that all weed seeds in the chaff fraction are assembled together with the chaff. The collection of loose chaff may require further treatments besides the field, which comes along with additional expenses. The necessary treatment depends on the chosen utilization pathway. The weed seeds contained in the loose chaff are still viable and need to be destroyed if fractions of the chaff are returned to the field somehow.

Removing chaff from the field may in some cases be unsustainable as it contributes to maintaining the water holding capacity and the fertility of the soil. The soil is a habitat for a vast, complex and interactive community of soil organisms whose activities largely determine the chemical and physical properties of the soil. In a fertile soil the soil biota may have a biomass exceeding $20 \mathrm{tha}^{-1}$ with life forms ranging from microscopic bacteria to the largest of earthworms [38]. However, still about $33 \%$ of the straw is normally left in the field and not harvested [9].

A larger fraction of straw could also be left in the field by harvesting higher or collecting less straw, which would be beneficial for the soil biota and compensate for the removed chaff.

\subsection{Thermal Treatment of Seeds}

The research with model seeds and ordinary weed seeds showed that seeds could be killed or severely damaged by heat treatments. Heat treatment with $250{ }^{\circ} \mathrm{C}$ for a few seconds reduced the germination ability substantially. Jakobsen et al. [38] treated eight common weed species in Northern European crops with exhaust gas with temperatures of $75^{\circ} \mathrm{C}, 85^{\circ} \mathrm{C}, 110^{\circ} \mathrm{C}$ and $140^{\circ} \mathrm{C}$ for 2,4 , and $6 \mathrm{~s}$. They found that $75^{\circ} \mathrm{C}$ and $85^{\circ} \mathrm{C}$ was insufficient to reduce germination of the seeds significantly at all three durations. Seed treatments with $110^{\circ} \mathrm{C}$ gave varying results depending on the duration and the weed species. Some seeds of $A$. myosuroides, $C$. cyanus and Lapsana communis L. were still able to germinate after $4 \mathrm{~s}$ exposure of $110^{\circ} \mathrm{C}(13,21$ and $11 \%$ germination, respectively). An exposure of 
$140{ }^{\circ} \mathrm{C}$ for 4 and $6 \mathrm{~s}$ repressed germination of all species. In our experiment, C. cyanus seeds were mixed with the chaff, and higher temperatures were needed to kill or reduce seed germination as chaff partly insulated the seeds from the heat. Separation of the seeds from the chaff (e.g., with a sieving system in/or underneath the combine harvester) before the seeds are heat treated would reduce the temperature needed to damage the seeds. A separation underneath the combine harvester possibly makes heat treatments unnecessary, because weed seeds could then easily be removed from the field because of the limited biomass of weed seeds compared to the biomass of chaff with weed seeds.

The moisture content may also vary in chaff and weed seeds (seeds can be more or less mature), and wetter material will require more energy. Some restrictions exist concerning the available heat inside the combine harvester and limited residence time because of harvesting velocity.

Another limitation for implementing an online heat treatment system is the available heat of the exhaust gas. If the moisture content of the harvested material is high, the temperature may not be high enough to heat the seeds until the core reached $80^{\circ} \mathrm{C}$. Too high moisture contents would lead only to surface evaporation without affecting the germination ability of the weed seeds. However, a temperature of $75-85{ }^{\circ} \mathrm{C}$ may release the dormancy of some weed species [39] and make them sensitive to weed control before the new crop emerged instead of being incorporated into the soil seed bank. Long-term surveys are necessary to evaluate the impact of weed seed harvest control on the soil seed bank of the different weed species.

The eco-toxicological impact of exposing chaff to exhaust gas needs to be investigated. Bringing toxic components to agricultural fields should be avoided under all circumstances. Online heat treatments of weed seed with or without chaff either with radiative, convective heat or exhaust gas inside a combine harvester is in principle possible, but further research is necessary to establish this as an appropriate alternative to current harvesting methods.

\section{Conclusions}

Weed species differ in seed shattering patterns. Some species like G. aparine retains all seeds on the plants until harvest while other species retain less at wheat harvest like B. hordeceus and C. arvense, which only retained about $40 \%$ and $11 \%$ in the year the seeds were counted, respectively. Therefore, the effect of collecting or/and destroying weed seeds during grain harvest depends on the composition of the weed flora in the field. For species retaining a large part of their seeds at harvest, weed seed harvest could probably contribute significantly to reduce weed infestation. As weed seeds mainly end in the chaff fraction during grain harvesting, this fraction could be collected and moved from the field. Placing the chaff on the straw swaths during the harvesting, and bale straw and chaff together showed to have some limitations, because a fraction of the weed seeds past through the straw swath and ended on the ground. However, thermal treatment of chaff containing weed seeds with exhaust gas from a grain harvester was successful. Exposing chaff and seeds for exhaust gas with a temperature of $150^{\circ} \mathrm{C}$ for less than ten seconds reduced seed germination significantly. Thermal weed seed control during harvesting could potentially be applicable and incorporated in an integrated weed management approach but require a new design of grain harvesters.

Author Contributions: Z.B. and C.A. investigated the shedding of weed seeds and did the germination experiments with C. cyanus in heat treated chaff. C.V. and J.R. were responsible for the field experiments with the combine harvester in Germany. C.G. and J.F. did the simulation studies and the heat treatments. C.A. wrote the first draft of the manuscript. All authors reviewed and accepted the manuscript.

Funding: This work was done as a part of the project Sweedhart - Separation of weeds during harvesting and hygienisation to enhance biomass production in the long term. Sweedhart is a transnational research project funded in the frame of the ERA-NET Cofund FACCE SURPLUS (Sustainable and Resilient Agriculture for Food and Non-food Systems), which is formed in collaboration between the European Commission and a partnership of 15 countries in the frame of the Joint Programming Initiative on Agriculture, Food Security and Climate Change (FACCE-JPI). FACCE SURPLUS is committed to improve collaboration across the European Research Area in the range of diverse, but integrated, food and non-food biomass production and transformation systems, including bio-refining. We thank the German Federal Ministry of Education and Research (project number 031B0164A and 031B0164B). 
Acknowledgments: The authors are grateful to the students of Fraunhofer UMSICHT for their helpful cooperation, namely Barbara Weiß, Ruth Schlautmann, and Markus Thiele.

Conflicts of Interest: The authors declare no conflict of interest. The funders had no role in the design of the study; in the collection, analyses, or interpretation of data; in the writing of the manuscript, or in the decision to publish the results.

\section{References}

1. Peterson, M.; Collavo, A.; Ovejero, R.; Shivrain, V.; Walsh, M. The challenge of herbicide resistance around the world: A current summary. Pest Manag. Sci. 2018, 74, 2246-2259. [CrossRef]

2. Heap, I. The International Survey of Herbicide Resistant Weeds, Online, Internet, Tuesday. 16 January 2018. Available online: www.weedscience.org (accessed on 20 December 2018).

3. Andreasen, C.; Streibig, J.C. Evaluation of changes in weed flora in arable fields of Nordic countries-Based on Danish long-term surveys. Weed Res. 2010, 51, 214-226. [CrossRef]

4. Duke, S.O. Why have no new herbicide modes of action appeared in recent years? Pest Manag. Sci. 2012, 68, 505-512. [CrossRef]

5. Anon. European Parliament Resolution of 13 September 2018 on the Implementation of the Plant Protection Products Regulation (EC) No 1107/2009 (2017/2128(INI)). Available online: http://www.europarl.europa.eu/ doceo/document/TA-8-2018-0356_EN.html?redirect (accessed on 2 May 2019).

6. Andreasen, C.; Stryhn, H. Increasing weed flora in Danish beet, pea and winter barley fields. Crop Prot. 2012, 36, 11-17. [CrossRef]

7. Andreasen, C.; Stryhn, H. Increasing weed flora on Danish arable fields and its importance for biodiversity. Weed Res. 2008, 48, 1-9. [CrossRef]

8. The Intergovernmental Panel on Climate Change (ICCP). Special Report, Global Warming at $5^{\circ}$ C. 2018. Available online: https://www.ipcc.ch/sr15/ (accessed on 20 December 2018).

9. Weiser, C.; Zeller, V.; Reinicke, F.; Wagner, B.; Majer, S.; Vetter, A.; Thraen, D. Integrated assessment of sustainable cereal straw potential and different straw-based energy applications in Germany. Appl. Energy 2014, 114, 749-762. [CrossRef]

10. McCartney, D.; Block, H.; Dubeski, P.; Ohama, A. Review: The composition and availability of straw and chaff from small grain cereals for beef cattle in western Canada. Can. J. Anim. Sci. 2006, 8, 443-455. [CrossRef]

11. EUROSTAT. Wheat and Spelt by Area, Production and Humidity. 2018. Available online: http://ec.europa.eu/eurostat/tgm/refreshTableAction.do;jsessionid=eH4_MMw5my4ZJsLm9XGH-

vHfBwdw157X2k8Dc6MFqgjMIlC62ouD!1614172686?tab=table\&plugin=1\&pcode=tag00047\&language= en (accessed on 21 December 2018).

12. Kiš, D.; Jovičić, N.; Matin, A.; Kalmbura, S.; Vila, S.; Guerac, S. Energy value of agricultural spelt residue (Triticum spelta L.) -Forgotten cultures. Tech. Gaz. 2017, 24, 369-373.

13. Wiwart, W.; Bytner, M.; Graban, L.; Lajszner, W.; Suchowilska, E. Spelt (Triticum spelta) and Emmer (T. dicoccon) Chaff Used as Renewable Source of Energy. BioResources 2017, 12, 3744-3750. [CrossRef]

14. Grube, J.; Böckelmann, M. The harvest home and dry-Key figures for grain drying. Landtechnik 2011, 66, 276-281.

15. Walsh, A.; Harrington, R.; Powles, S. Harrington Seed Destructor: A new nonchemical weed control tool for global grain crops. Crop Sci. 2012, 52, 1343-1347. [CrossRef]

16. Walsh, M.; Newman, P. Burning narrow windrows for weed seed destruction. Field Crops Res. 2007, 104, 24-30. [CrossRef]

17. Walsh, M.; Ouzman, J.; Newman, P.; Powles, S.; Llewellyn, R. High levels of adoption indicate that harvest weed seed control is now an established weed control practice in Australian cropping. Weed Technol. 2017, 31, 341-347. [CrossRef]

18. McLeod, R. Harvesting System and Method. Patent CA2180691C, 8 July 1996.

19. Rumpler, J. Method and Device for Harvesting Threshed Crops. Patent US8961286B2, 19 March 2010.

20. Clayton, W.D.; Vorontsova, M.; Harman, K.T.; Williamson, H.; Bromus Hordeaceus. GrassBase-The Online World Grass Flora. 2018. Available online: https://www.kew.org/data/grasses-db/www/imp01633.htm (accessed on 21 December 2018). 
21. Moore, R.J. The biology of Canadian weeds. 13. Cirsium arvense (L.) Scop. Can. J. Bot. 1975, 55, $1033-1048$. [CrossRef]

22. Malik, N.; Vandenborn, W.H. The biology of Canadian weeds. 86. Galium aparine L. and Galium spurium L. Can. J. Plant Sci. 1988, 68, 481-499. [CrossRef]

23. SAS Institute 2019. Available online: http://support.sas.com/software/94/index.html (accessed on 10 January 2018).

24. Kwon, Y.M.; Bang, H. The Finite Element Method Using Matlab, 2nd ed.; CRC Press: Boca Raton, FL, USA, 2000; p. 624. ISBN 978-1-42-004188-0.

25. Baker, K.F. Principles of heat treatment of soil and planting material. J. Aust. Inst. Agric. Sci. 1962, 28, 118-126.

26. Van Loenen, M.C.A.; Turbett, Y.; Mullins, C.E.; Wilson, M.J.; Feilden, N.; Seel, W.E. Low Temperature/Short Duration Steaming as a Sustainable Method of Soil Disinfection. In Proceedings of the UK Organic Research 2002 Conference, Aberystwyth, UK, 26-28 March 2002; pp. 211-214.

27. Andreasen, C.; Bitarafan, Z.; Fenselau, J.; Glasner, C. Exploiting waste heat from combine harvesters to damage harvested weed seeds and reduce weed Infestation. Agriculture 2018, 8, 42. [CrossRef]

28. Holm-Nielsen, C. Frø Fra Det Dyrkede Land. Forskningscenter Flakkebjerg; Ministeriet for Fødevare, Landbrug or Fiskeri: Frederiksberg, Denmark, 1998.

29. DMI, Vejrarkiv 2018. Available online: https://www.dmi.dk/vejr/arkiver/ (accessed on 2 May 2019).

30. Bitarafan, Z.; Andreasen, C. Seed production and shedding of Alopecurus myosuroides (blackgrass) and Apera spica-venti (windgrass) and its importance for weed seed harvest control. Weed Sci. 2019. submitted.

31. Walsh, M.J.; Powles, S.B. Management strategies for herbicide-resistant weed populations in Australian dryland crop production systems. Weed Technol. 2007, 21, 331-338. [CrossRef]

32. Blanco-Moreno, J.M.; Chamorro, L.; Masalles, R.M.; Recasens, J.; Sans, F.-X. Spatial distribution of Lolium rigidum seedling following seed dispersal by combine harvesters. Weed Res. 2004, 44, 375-387. [CrossRef]

33. Barroso, J.; Navarrete, L.; Sanchez Del Arco, M.J.; Fernandez-Quintanilla, C.; Lutman, P.J.W.; Perry, N.H.; Hull, R.I. Dispersal of Avena fatua and Avena sterilis patches by natural dissemination, soil tillage and combine harvesters. Weed Res. 2006, 46, 118-128. [CrossRef]

34. Shirtliffe, S.J.; Entz, M.H.; Van Acker, R.C. Avena fatua development and seed shatter as related to thermal time. Weed Sci. 2000, 48, 555-560. [CrossRef]

35. Feldman, M.; Reed, W.B. Distribution of wild oat seeds during cereal crop swathing and combining. In Proceedings of the Annual meeting of the Canadian Society of Agricultural Engineering, Quebec City, QC, Canada, 4-8 August 1974; pp. 1-10.

36. Balsari, P.; Finassi, A.; Airoldi, G. Development of a device to separate weed seeds harvested by a combine and reduce their degree of germination. In Proceedings of the 12th World Congress of the International Commission of Agricultural Engineers, Milano, Italy, 28 August-1 September 1994; pp. 562-573.

37. Weiß, B.; Glasner, C. Evaluation of the process steps of pretreatment, pellet production and combustion for an energetic utilization of wheat chaff. Front. Environ. Sci. Agroecol. Land Use Syst. 2018. [CrossRef]

38. Lee, K.E.; Pankhurst, C.E. Soil organisms and sustainable productivity. Aust. J. Soil Res. 1992, 30, 855-892. [CrossRef]

39. Jakobsen, K.; Jensen, J.A.; Bitarafan, Z.; Andreasen, C. Killing weed seeds with exhaust gas from a combine harvester. Crop Prot. 2019, Submitted.

(C) 2019 by the authors. Licensee MDPI, Basel, Switzerland. This article is an open access article distributed under the terms and conditions of the Creative Commons Attribution (CC BY) license (http://creativecommons.org/licenses/by/4.0/). 